\title{
La contemplación del rostro como camino místico en De visione Dei de Nicolás de Cusa
}

\author{
Lorena Basualto Porra \\ FACULTAD ECLESIÁSTICA DE TEOLOGÍA \\ PONTIFICIA UNIVERSIDAD CATÓLICA DE VALPARAÍSO \\ lorenabasualto@yahoo.es
}

\section{INTRODUCCIÓN}

La veneración de una imagen que representa la divinidad suele ser un acto de devoción común en la vida cristiana, ya que para el creyente ver el rostro del amado, contemplarlo como él es, constituye sin lugar a duda, la dicha suprema ${ }^{1}$.

Esta constatación permite aventurar que una acción tan simple, aparentemente, como es ver el rostro divino plasmado en un ícono, puede ser el comienzo de un verdadero espacio de encuentro místico; entendiendo este, en sentido amplio, como la relación que se da entre un sujeto, que se esfuerza por alcanzar un objeto místico con un proceso apropiado $^{2}$.

El presente estudio, se sustenta en el presupuesto que se puede comprender esta práctica devocional al modo de un itinerario místico como lo hace Nicolás de Cusa en su obra De visione Dei . Esta premisa se sos-

1 Cf. W. Beierwaltes, Cusanus. Reflexión metafísica y espiritualidad (EUNSA, Pamplona, 2005) 211.

2 Ch. Bernard, Teología mística (Monte Carmelo, Burgos, 2006) 73.

3 De visione Dei, fue escrita en el año 1453 a petición del abad del convento benedictino de Tegernsee, Gaspar Aindorffer; Cf. A. GonzÁlez, Introducción De visione Dei, en Nicolás de Cusa, La visión de Dios (EUNSA, Pamplona, ${ }^{5} 2007$ ) 11-12. Esta obra ha sido catalogada por los estudiosos como la obra de talante más mística del Cardenal; Cf. J. André, "Mística y conocimiento de Dios en Nicolás de Cusa y en su tratado De visione Dei”, en M. Álvarez (ed.), Problemas fundamentales del conocimiento (Sociedad Castellano-Leonesa de filosofía, Salamanca, 1993) 
tiene a partir de lo que expresa el mismo autor, al principio de su obra, cuando señala que va a ocupar un método experiencial para mostrar la accesibilidad que todo creyente puede tener a la teología mística ${ }^{4}$. Este procedimiento se inicia con la contemplación de una imagen de Dios que lo ve todo, cuyo rostro ha sido pintado tan hábilmente, que parece ver todo lo que lo circunda a través de una mirada que tiene las características de ser Inmutable, Inabarcable, Omnipresente y Omniprovidente 5 .

De este modo, el presente artículo pretende descubrir el itinerario místico que Nicolás de Cusa propone, en De visione Dei, para encontrarse con el Dios de Jesucristo a través de la contemplación de un ícono. Tal itinerario no es presentado explícitamente en la obra, por lo tanto, va a ser necesario escudriñar el texto focalizándonos en este tema y de esa forma llegar a definir algunas etapas del camino místico propuesto por el cusano.

Para lograr dicho propósito se ordenará el artículo en cinco acápites. En primer lugar, se tratará el tema de la mirada Infinita; luego, se presentará la experiencia de la mirada finita que se proyecta hacia el Infinito; en tercer lugar, el mirarse a sí mismo desde el Infinito; posteriormente, se hará referencia a las fuerzas de atracción y de deseo; para, finalmente, presentar un esbozo sistemático del camino místico de la contemplación del rostro.

103-124. Para el análisis de la obra se dispuso de Nicolai De Cusa, Opera omnia De visione Dei, (Felicis Meiner, Hamburgi, 2000) y la traducción en español del profesor Ángel Luis Gonzáles: Nicolás de Cusa, La visión de Dios (EUNSA, Pamplona, ${ }^{5}$ 2007), en adelante De visione Dei $=$ VD.

4 Cf. VD 1. Con respecto al tema místico algunos autores relacionan a Nicolás de Cusa con el movimiento de la Devotio Moderna y lo presentan como discípulo de Gerhart Groote por lo que el cusano sería heredero de la mística medieval que se desarrolla entre finales del siglo XIII y el siglo XIV. Al respecto Cf. J. ILlanes - J. Saranyana, Historia de la Teología (BAC, Madrid, 2002) 103-105; J. SÁnchez, Historia de la Iglesia II: Edad Media (BAC, Madrid, 2005) 519-520. Con respecto a estudios específicos sobre la teología mística del cusano ver: W. Hoye, Die mystische theologie des Nicolaus Cusanus (Herder, Breisgau, 2004); N. Vollmer, Erkenntnis und Mystik bei Nokolaus von Kues (GRIN, Karlsruhe, 2005); A. HAAs, Nikolaus von Kues als Mystiker (Paulinus-Verlag, Trier, 2008); W. Euler - K. Reinhardt - H. Schwaetzer - M. Vannier (dirs.), Encyclopédie des Mystiques Rhénans. D'Eckahrt à Nicolas de Cues et leur réception (Cerf, Paris, 2011).

5 Cf. VD 2. 
Por último, es necesario constatar, que el estudio pretende ser un aporte a la comprensión del pensamiento de Nicolás de Cusa, quien es capaz de desarrollar en una obra mística temas teológicos complejos como la visión de Dios en sí misma, la Infinitud, la Trinidad y Cristo ${ }^{6}$; todo ello, dentro de un marco experiencial de visión sensible, racional e intelectual, que se proyecta hacia la vivencia mística del misterio de Dios $^{7}$. Desde aquí se puede hacer un aporte teológico-pastoral, en el sentido de constatar las distintas fases del encuentro místico, lo que quedará explícito al final del artículo.

\section{LA EXPERIENCIA DE LA MIRADA INFINITA}

Desde el principio de su obra Nicolás de Cusa quiere llamar la atención sobre el hecho de que cuando el yo finito se dispone a contemplar al Dios Infinito, no es que el ser humano por su propia capacidad tenga la posibilidad de observar el rostro divino, puesto que sin la visión absoluta no podría existir una visión limitada; por lo tanto, el acto primero lo realiza Dios pues él es propiamente theos ${ }^{8}$ en cuanto lo ve todo. De este modo, la experiencia del encuentro entre el Infinito y el finito, se debe ilustrar como un movimiento que parte desde Dios hacia hombre.

Ahora bien, la acción de Dios no se reduce solamente al ver, pues de lo que se afirma de uno de los atributos de Dios, se dice también de otros, debido su suprema Simplicidad ${ }^{2}$. Al respecto el Cardenal señala:

"Señor, tu ver es amar; y lo mismo que tu mirada se dirige a mí tan atentamente que nunca se separa de mí, del mismo modo también tu amor. Y como tu amor está siempre conmigo, y tu amor, Señor, no es

$6 \quad$ A la luz de la lectura de la obra, se visualiza una estructura del corpus del texto que propiamente el autor no lo realiza. Se puede considerar que los primeros capítulos corresponden a una presentación de la obra (n.1), luego el autor escribe un Prefacio (n. 2-4) y posteriormente trata las implicancias teológicas de nombrar a Dios como theos (n. 5-8). En el corpus mismo de la obra se pueden distinguir cuatro secciones, a saber: Sección A, capítulos IV-XII (n. 9-50), que trata del tema de la visión de Dios; Sección B, capítulos XIII-XVI (n. 51-70), que presenta la infinitud de Dios; Sección C, capítulos XVII-XVIII (n. 71-82), que aborda el tema de la Trinidad; Sección D, capítulos XIX-XXV (n. 83-119), donde se desarrolla su pensamiento cristológico.

7 Cf. VD 1.

8 Cf. VD 5.

9 Cf. VD 8. 
distinto de ti mismo, que me amas, por eso tú estás siempre conmigo, Señor. Tú no me abandonas, Señor; me proteges en todas partes, ya que tienes una esmeradísima solicitud por mí. Tu ser, Señor, no abandona mi ser. Soy, en efecto, en tanto en cuanto tú estás conmigo. Y puesto que tu ver es tu ser, yo soy porque tú me miras. Si quitase tu rostro de mí, en absoluto continuaría existiendo" ${ }^{10}$.

El cusano relaciona el ver de Dios estrechamente con el amor, así como Dios mira al hombre, del mismo modo le ama y le da el ser, lo que se opone radicalmente al abandono existencial, que le llevaría irremediablemente a la nada ${ }^{11}$. Esta relación ontológica, en cuanto que el Infinito da el ser al finito, tiene la característica particular de ser un vínculo amoroso, lo que se aleja totalmente de una relación meramente metafísica para orientarse más bien a una reciprocidad de tipo personal ${ }^{12}$.

Esta comunión personal entre el Infinito y el ser finito, se da de una manera tan íntima que parece ser exclusiva, como si se abriese un punto en la creación donde solo existiese Dios y yo ${ }^{13}$. Incluso más, el Cardenal es enfático en afirmar que Dios "nunca cierras los ojos"14; usa esta imagen plástica para señalar que el hombre debe su ser, solo y exclusivamente, a la mirada de Dios. De allí que, antropológicamente, se podría afirmar que el hombre, para el cusano, es constitutivamente aquel que se sabe mirado por Dios; y, al mismo tiempo, va experimentando que Dios se deja mirar. Esa es la experiencia de Israel, pues el pueblo a largo de su historia va a ir constatando esto; desde allí, se ha planteado que el nombre de Israel, con el cual Dios denomina a Jacob, después de haber luchado con él, más que fuerte contra Dios sería hombre que ve a Dios ${ }^{15}$. $\mathrm{Y}$ esto es muy importante, porque por medio del don divino, se rompe

10 VD 10.

11 "Suprimido el infinito, no queda nada", VD 55. Esta idea es recurrente en el cusano, Cf. Nicolás de Cusa, De docta ignorantia, trad. Manuel Fuentes (Orbis, Buenos Aires, 1984) II, 3; Nicolás de Cusa, De possest, trad. Ángel Luis González (EUNSA, Pamplona, 2001) 57.

12 Cf. A. MeIs, Antropología Teológica, Acercamiento a la paradoja del hombre (PUC, Santiago, $\left.{ }^{2} 2001\right) 67$.

13 Cf. VD 27.

14 VD 14.

15 Cf. A. Meis, Antropología Teológica..., 135. 
La contemplación del rostro como camino místico en De visione Dei de Nicolás de Cusa 465

la concepción de un Dios que de por sí está oculto ${ }^{16}$, para pasar a otra donde Dios se deja encontrar por aquellos que lo buscan con rectitud de corazón ${ }^{17}$.

De esta manera, Nicolás de Cusa sostiene que justamente es Dios el que posibilita la mirada, de allí que señale a modo de testimonio:

"Viéndome, tú que eres Dios escondido, me concedes que tú seas visto por mí. Nadie puede verte sino en cuanto tú le concedes que seas visto. Y verte no es otra cosa que tú ves al que te ve. En esta imagen tuya veo cuántos te has abajado, Señor, para mostrar tu rostro a todos los que te $\operatorname{aman}^{\prime \prime} 18$.

El cusano sitúa la posibilidad del encuentro en el mismo acto visivo de Dios, de modo que, en la medida que Dios me mira, yo lo puedo mirar a él. De este modo, Nicolás de Cusa, abre el misterio del Dios escondido, que de suyo no es visible para el hombre, pero que se deja ver por medio de la visión divina que, propiamente, es gracia divina ${ }^{19}$. Así pues, solo desde la gracia se puede contemplar el misterio inefable, pues allí el Infinito entra en relación con el ser finito; ya que, para el cusano, la divinidad se abaja para hacer posible el encuentro de la creatura con el Creador.

\section{EXPERIENCIA DE LA MIRADA FINITA QUE SE PROYECTA HACIA EL INFINITO}

La mirada Infinita posibilita la experiencia de la mirada finita. En esta dinámica Dios se entrega plenamente al hombre a través de su mi-

16 Esta convicción la sintetiza extraordinariamente el profeta Isaías cundo dice: "De cierto que tú eres un dios oculto, el Dios de Israel, salvador", Is 45,15. De hecho Nicolás de Cusa en su obra De Deus absconditus de 1444 comenta este texto de Isaías. Cf. C. D’Amico, "El Deus absconditus o acerca del nombre de Dios en Nicolás de Cusa”, en Patristica et mediaevalia XVII (1996) 38.

17 Es lo que señala el profeta Jeremías cuando hace hablar al mismo Dios y dice: "Me buscaréis y me encontraréis cuando me solicitéis de todo corazón”, Jer 29,13. La misma experiencia la relata el profeta Isaías cuando exhorta: "Buscad a Yahveh mientras se deja encontrar, llamadle mientras está cercano”, Is 55, 6.

18 VD 13-14.

19 Pensamiento que posteriormente va a consolidar notablemente en el De possest cuando señala que Dios "no podrá ser visto a menos que la posibilidad de ser visto sea llevada al acto por aquel que es la actualidad de toda potencia mediante una manifestación de sí mismo, pues Dios está oculto y escondido a los ojos de todos los sabios, pero se revela a los pequeños o humildes, a los que concede su gracia”, Nicolás de Cusa, De possest, 31. 
rada y este último se ve movido a dar una respuesta a esta invitación vital. En este contexto el acto devocional, de contemplar el rostro de Dios, no es presentado por el Cardenal como un acto simple y sencillo, de allí se entiende que, a lo largo de esta obra, él destaque la complejidad teológica que dicho acto comporta. Al respecto y a modo de un presupuesto antropológico básico, el cusano es enfático en señalar que la visualización que el hombre hace de Dios no es, propiamente, un acto corporal, pues no son los ojos materiales los que se deben ocupar para mirar a Dios, sino que son más bien los ojos mentales e intelectuales los que operan en este ámbito contemplativo ${ }^{20}$.

Por este motivo Nicolás de Cusa sostiene que la mirada finita tiene características especiales, ya que, para el hombre, el hecho de ver a Dios no es una acción cotidiana ni evidente. Por eso sostiene la necesidad de un camino contemplativo que se inicia a través de la vía experiencial, dada por el hecho de contemplar el ícono, lo cual permite adentrarse en la sacratísima oscuridad, pero la paradoja está, en que estando en este lugar se experimenta la luz inaccesible ${ }^{21}$.

Para evidenciar la posibilidad que el hombre tiene de penetrar en la oscuridad luminosa de Dios, Nicolás de Cusa hace referencia a la experiencia mística de San Pablo que consigna en la Segunda Epístola a los Corintios ${ }^{22}$, en ella el Apóstol señala que sabe de un hombre que fue arrebatado hasta el tercer cielo, o sea al paraíso, y allí oyó palabras inefables que el hombre no puede pronunciar. Esta experiencia paulina el cusano la presenta en De visione Dei de la siguiente manera:

"Tú, Dios, me has revelado esto: que ni el oído oyó, ni hasta el corazón del hombre ha descendido la infinitud de tu dulzura, que tienes preparada para los que te aman. Esto nos lo reveló Pablo, tu gran apóstol, que allende el muro de la coincidencia fue arrebatado al paraíso, en donde únicamente puede ser visto de modo manifiesto, tú que eres la fuente de las delicias" ${ }^{\prime 2}$.

20 Cf. VD 111-112.

21 VD 1. En este aspecto Nicolás de Cusa sigue totalmente a Dionisio, Cf. Dionisio Areopagita, Obras completas (BAC, Madrid, 2007) Epístolas 5.

22 Cf. 2Co 12,2-4.

23 VD 79. 
A partir de esta cita, es posible referirse a dos aspectos que parecen importantes a la hora de abordar la mística en el cusano. En primer lugar, se sostiene la premisa que el ser humano no puede acceder plenamente al misterio de Dios; de hecho, en la última de sus obras, De apice theoria, comenta que "si el apóstol Pablo, arrebatado al tercer cielo, no llegó a comprender lo incomprensible, nadie jamás llegará a saciarse con lo que es mayor que toda comprensión, sino que se dedicará afanosamente siempre a intentar comprenderlo mejor" ${ }^{24}$. Entonces, he aquí la segunda premisa: en la pretensión del ser humano de aprehender a Dios el único camino que le queda es poder comprender, de la forma más sublime posible, pero no total, el misterio de Dios.

Para dar cuenta de esta realidad el cusano acuña un lenguaje simbólico propio para poder referirse a este misterio, recurriendo a la imagen del muro, donde el hombre se encuentra a un lado de este impedido de acceder al paraíso. Pero, al mismo tiempo, en este lado del muro se puede contemplar a Dios como creador y ver su rostro en las creaturas; ya que, Dios al llamar de la nada al ser, le ha comunicado propiamente su $\operatorname{ser}^{25}$. De allí que, el cusano, señale que Dios es a la vez invisible y visible, teniendo presente que lo invisible es lo propio de él, pero que se hace visible en las creaturas ${ }^{26}$. De este modo, las creaturas se constituyen en el real y vivo icono divino, en cuanto que posibilitan que lo invisible sea haga visible, siempre que las creaturas estén de cara a $\operatorname{Dios}^{27}$.

He aquí un aspecto importantísimo, en cuanto a la posibilidad que el ser finito pueda mirar al Infinito, por lo que, necesariamente, en la relación entre el yo y Dios aparecen los otros, es decir, la condición de alteridad. Así pues, por el hecho de no ser el Infinito, tengo la condición

24 Nicolás De Cusa, De apice theoriae, trad. Ángel Luis González (EUNSA, Pamplona, 2001) 2.

25 Cf. VD 49.

26 Cf. VD 47. En este sentido el cusano sigue a San Pablo en la carta a los Romanos cuando señala que "lo invisible de Dios, desde la creación del mundo, se deja ver a la inteligencia a través de sus obras", Rm 1,19.

27 Según el profesor Ganoczy esta forma de ver la creación por el cusano tiene sus raíces en Eckhart cuando en su obra Deutsche Predigten und Traktate, señala: "Dios se hace Dios allí donde todas las creaturas lo reflejan: en ese momento Dios se hace Dios". A. Ganoczy, La trinidad creadora (Secretariado Trinitario, Salamanca, 2005) 144 . 
de ser otro para los que no son $\mathrm{yo}^{28}$, es lo que Nicolás de Cusa llama alteridad, en tanto condición de ser otro ${ }^{29}$.

Según lo anterior, la relación que se da entre la mirada finita y la Infinita no es totalmente inmediata, sino que pasa por los otros que no son yo, de allí que en la mirada finita necesariamente debe incorporarse la mediación del alter y, solo de esa manera, llegar a la visión del Dios Infinito. Para comprender esta realidad, el cusano, utiliza el ejemplo del nogal que permite ver la fuerza de la simiente y desde allí ver su causa ${ }^{30}$. Es decir, el hecho que exista multiplicidad permite ver la potencia de las potencias, en el sentido que remite a Dios, el cual es el modelo: Absoluto, Simplísimo, Infinito, Verísimo, Adecuadísimo ${ }^{31}$.

Entonces, si bien es cierto tenemos toda la creación para ver el rostro de Dios, hasta el momento no hemos cruzado totalmente el muro. Ciertamente, puedo conocer por medio de las creaturas al Infinito, porque es el creador, o sea, desde los efectos a las causas y se puede ir desde las causas a los efectos ${ }^{32}$; sin embargo, contemplar a Dios como el rostro de los $\operatorname{rostros}^{33}$, se puede hacer solamente de una forma velada o mediada.

La pregunta que le podemos hacer al Cardenal es cómo se puede atravesar el muro, o bien, si existe la posibilidad de encontrar un camino para ver el esplendor del rostro de Dios. Para responder vamos a continuar con el pasaje, de De visione Dei, donde el cusano se refiere a la experiencia mística de San Pablo:

28 Uno de los nombres que da Nicolás de Cusa a Dios es justamente el de non-Aliud, ver al respecto Nicolás de Cusa, El no otro, trad. Ángel Luis González (Cuaderno de Anuario Filosófico, Pamplona, 2005).

29 "En efecto la alteridad se nombra a partir del no ser. Precisamente por el hecho de que una cosa no es otra, se dice que es otra [...] la alteridad por consiguiente no es algo", VD 58.

30 El autor pone el ejemplo de un nogal, en cuanto al contemplar todos sus accidentes me lleva a un potencial que es la causa del despliegue de todo el árbol, y desde allí puedo derivarlo a todos los árboles. De allí que concluye: "el árbol eres tú mismo, mi Dios; y en ti está su verdad y su modelo. Igualmente, también el germen del árbol es en ti la verdad y ejemplar de sí mismo. Tú, Dios, eres la verdad y ejemplar tanto del árbol como del germen”, VD 24.

31 Cf. VD 34.

32 Cf. VD 46.

33 Cf. VD 20. 
"Confiando en tu infinita bondad, he intentado someterme a ese arrebato, para verte a ti que eres invisible, y tener una visión revelada de ti que eres irrevelable. Pero donde haya llegado, tú lo sabes; yo, en cambio, no lo sé. Me basta tu gracia, con la que me haces estar cierto de que tú eres incomprehensible, y por la que me elevas a la firme esperanza de que llegaré, bajo tu guía, a la fruición de ti” ${ }^{34}$.

Para el cusano, la única forma de comprensión sublime de lo Infinito es estar de alguna manera en el Infinito y, ciertamente, esto es un don, puesto que el yo por sí mismo no lo alcanza y necesita ser arrebatado como Pablo al paraíso. El grado de acercamiento que puede llegar a tener el hombre con la divinidad es desconocido y es, en este contexto, cuando afirma el cusano con vehemencia que le basta la gracia de Dios para acceder a dos elementos básicos que esta regalaría al hombre: primero, la certeza absoluta de la incomprensibilidad de Dios; y segundo, que contamos con la guía divina que hace posible, finalmente, el encuentro entre Dios y el hombre. De modo que, en este cruce de miradas, se debe agregar un elemento significativo que es la gracia. Ella permite al hombre reconocer que Dios es incomprensible; lo cual, a primera vista, pareciera que no aporta mucho, de cara al propósito final que es llegar a la visión de Dios; sin embargo, esta afirmación, aparentemente contradictoria, no es tal porque Nicolás de Cusa sitúa en lo incomprensible una paradoja. Sostiene que si el hombre quiere acceder a Dios es necesario que el intelecto se haga ignorante y, de esa forma, se sitúe en la sombra, a partir de ello se pregunta: “¿Pero qué es, Dios mío, un intelecto en la ignorancia? ¿No es acaso la docta ignorancia?”35.

Para el cusano, la docta ignorancia ${ }^{36}$, es una realidad que refleja nuestra condición antropológica ante el ser y la verdad, pues el hombre necesita reconocer, en primer lugar, su pequeñez si quiere contemplar en

34 VD 79.

35 VD 52.

36 El cusano tratará ampliamente este asunto en su obra más conocida De docta ignorancia, con respecto a la obra señala: "En este primer libro intentaré inquirir incomprensiblemente por encima de la razón humana este máximo, en el que se cree por la fe de modo indudable como Dios de todas las naciones, con la guía de aquel que solo habita la luz inaccesible" Nicolás De CusA, De docta ignorantia, L. 1, cap. II. Con respecto a la docta ignorantia como punto de partida de la filosofía de Nicolás de Cusa, es interesante ver el artículo de E. Vallinas, "El punto de partida en la filosofía de Nicolás de Cusa”, en Sapientia XVI (1959) 299-304. 
algo este misterio ${ }^{37}$. En este sentido, comenta el profesor Beierwaltes que Nicolás de Cusa es heredero del neoplatonismo cuando sostiene que el primer principio de todo ente es incomprensible e inefable en su esencia, de allí que Dios posea esta cualidad ${ }^{38}$. Sin embargo, este abismo que existe entre ser y logos, no es para el cusano un problema a resolver sino una realidad que aceptar ${ }^{39}$, y a partir de aquí comienza su reflexión filosófica y teológica, y por qué no decir también la contemplación mística. Esto porque, en esta tensión permanente entre lo Infinito y lo finito, el cusano descansa en la gracia de Dios, la cual va a permitir en definitiva la esperanza del encuentro.

La pregunta sigue en pie, ¿cómo Dios se deja ver más allá del muro? Ciertamente, la única posibilidad es a través de la iniciativa graciosa de Dios y esta, para Nicolás de Cusa, es por excelencia Jesucristo, que es el mediador entre el Infinito y lo finito, ya que en él se unen la naturaleza divina y humana ${ }^{40}$, aunque a ambas realidades las separe un muro infranqueable ${ }^{41}$. En Cristo se hace posible el encuentro destruyendo este muro $^{42}$. De allí que el cusano exprese la felicidad que esta realidad conlleva, porque lo imposible humanamente se hace posible solo por la gracia, por eso afirma: "Todo espíritu feliz ve al Dios invisible, y en ti,

37 Cf. J. ANDRÉ, "Conocer es dialogar. La metáfora del conocimiento y su dimensión dialógica en el pensamiento de Nicolás de Cusa” en J. Machetтa - C. D’Amico (eds.), El problema del conocimiento en Nicolás de Cusa: genealogía y proyección (Biblos, Buenos Aires, 2005) 17.

38 Cf. W. Beierwaltes, Cusanus..., 89. 102.

39 Es lo que plantea el profesor Hubert, Cf. A. Meis, A. Hubert, J. Pachas, J. Pinilla, "Alteridad y misterio a la luz de la confluencia de fuentes griegas y latinas en Buenaventura, Alberto Magno, Nicolás de Cusa y Juan de la Cruz", en Anales de la Facultad de Teología, LIX (2008) 244. Al respecto es interesante el artículo de Diego de Zavalía quien plantea el tema del abismo como problema en la filosofía y cómo lo resuelve el cusano, Cf. D. Zavalía, "La filosofía ante el Abismo: la apropiación cusana”, en J. MaснеттA - C. D’Amico (eds.), El problema del conocimiento... , 407-409.

Cf. VD 89.

Cf. VD 46.

42 El profesor Miller concluye su artículo donde analiza De visione Dei, señalando que Cristo es aquel que da la posibilidad de traspasar el muro y por tanto permite al hombre la visión y la unión con Dios. Cf. C. Miller, "The icon and the wall: Visio and Ratio in Nicholas of Cusa's De visione Dei", en Proceeding of the American Catholic Philosophical Association 64 (1990) 98. 
Jesús, se une al Dios inmortal e inaccesible. Y así, lo finito se une en ti a lo infinito e inmutable" 43 .

Entonces, en Cristo, ya tenemos el camino para ver a Dios, situación que, en un primer momento, parecía lejana en cuanto a la imposibilidad humana de traspasar este muro, donde la gracia por excelencia es la propia autodonación de Dios a través del Hijo. Esta situación es llamada por el cusano descendimiento de Dios, el cual no pierde nada de su infinitud por el hecho de dejarse ver por los seres finitos. En este sentido, Nicolás de Cusa siempre salvaguardará el hecho que Dios no pierde sus cualidades eternas, como también que no agrega nada a ellas, sino que la manifestación de Dios se da en favor del hombre ${ }^{44}$. Tampoco se puede perder de vista el hecho que la realización plena del encuentro será en la visión definitiva, lo cual abre a la perspectiva escatológica, que ciertamente nutre el camino del cristiano como don definitivo de la gloria ${ }^{45}$.

De este modo, la gracia que viene de parte de Dios es propiamente Jesucristo, en este momento de la reflexión el cusano da un salto cualitativo, pues esta gracia no es solo una posibilidad epistemológica de ver a Dios, sino que además es una posibilidad ontológica de ser en Dios ${ }^{46}$. De modo que, en el Hijo, Dios regala una relación nueva, ya no solamente en términos de Infinito y finito, o entre el Creador y la creatura o entre Dios y el yo, sino que en Cristo surge propiamente una vinculación filial; es por eso que el cusano afirma que: "Tu paternidad es la visión que nos abarca paternalmente a todos; en efecto, decimos "padre nuestro». Tú eres igualmente padre de todos y de cada uno" ${ }^{37}$. Desde esta perspectiva aparecen nuevos sujetos en la escena de la contemplación mutua entre Dios y el hombre, que son el Padre y el Hijo, el cual nos hace partícipes de la adopción filial.

Ahora bien, esta posibilidad del encuentro, al otro lado del muro, solo se puede comprender desde la dimensión de la fe. En este sentido, el

\footnotetext{
3 VD 93.

44 Cf. VD 68.

45 Cf. VD 119.

46 Cf. VD 106.

47 VD, 27.
} 
mismo Nicolás de Cusa advierte que para los que se consideran sabios ${ }^{48}$ es muy difícil de admitir, porque pareciera que de Cristo se dicen cosas contradictorias en cuanto que es "creador y criatura, el que atrae y a la vez atraído, igualmente finito e infinito" ${ }^{49}$. En el fondo, lo que no se entiende ni tampoco se acepta, es la encarnación y las consecuencias que de ella se desprenden, en el sentido que se une lo divino y lo humano y, por lo mismo, se puede aplicar a la misma persona de Jesucristo cualidades que provienen de ambas naturalezas. Es lo que el cusano denomina coincidencia de los opuestos, de modo que en esta lógica no sería contradictorio decir que Cristo es tanto creador y creatura a la vez ${ }^{50}$.

La pregunta que se podría hacer al cusano es de qué modo se desarrolla este proceso de aceptar por la fe a Jesús, pues el tema es cómo el yo/ finito/hijo puede ver a Dios a través de Jesucristo, porque, ciertamente, el Cardenal no se está refiriendo a los contemporáneos del Maestro, sino de aquellos sujetos que hoy contemplan el misterio. $Y$ es en este punto cuando, nuevamente, Nicolás de Cusa sorprende señalando que:

"El Verbo de Dios está dentro del intelecto; no le es necesario al intelecto buscarlo fuera de sí mismo, ya que lo encontrará dentro y podrá acceder a él a través de la fe. Y con plegarias podrá alcanzar también la posibilidad de aproximarse más. En efecto, el Verbo le aumentará su fe a través de la comunicación de su luz" ${ }^{51}$.

Para el cusano el acceso al Dios/Infinito/Padre es a través del propio intelecto humano, por lo que el yolfinito/hijo no necesita buscar fuera de sí mismo, pues el Verbo le ilumina el entendimiento, lo mismo que la luz del sol a este mundo ${ }^{52}$, porque propiamente el Padre, afirma el Cardenal, nos ha dado a su Hijo como verdadero maestro, que es camino, vida y verdad, para que no nos faltara absolutamente nada ${ }^{53}$.

Entonces ¿`cómo concretamente se recibe esta luz? Es aquí donde $\mathrm{Ni}$ colás de Cusa presenta las Escrituras como aquellas que revelan a Cris-

48 Sigue la línea de San Pablo cuando señala: “¿Dónde está el sabio? ¿Dónde el docto? ¿Dónde el sofista de este mundo? ¿Acaso no entonteció Dios la sabiduría del mundo?", 1 Cor 1,20.

49 VD 91.

50 Nicolás de Cusa, De docta ignorantia, L.3, cap.II.

51 VD 113.

52 Cf. VD 100.

53 Cf. VD 118-119. 
to, pero no de una forma externa en cuanto que manifiestan verdades doctrinales, sino como un auténtico maestro interior que perfeccionará al hombre. Para que esta luz sea acogida necesita de la aceptación libre del ser humano y, por tanto, a través de la fe someterse a la Palabra de Dios $^{54}$. De este modo, aquel que se abre a la Palabra puede gozar del don divino que es el amor, la paz, el reposo ${ }^{55} \mathrm{y}$, por sobre todo, alcanzar la resurrección y la vida divina ${ }^{56}$. Además, se logra la comunión plena, pues el cusano está convencido que Cristo ha enseñado a los hombres, principalmente, dos cosas la fe y el amor: por la fe el intelecto alcanza al Verbo y a través del amor el hombre se puede unir a Jesús y al Padre ${ }^{57}$.

De este modo, se aporta un nuevo elemento a la comprensión de la posibilidad del encuentro, pues estamos frente a un hombre nuevo ${ }^{58}$, que ha adquirido una nueva dimensión espiritual al aceptar a Cristo por la fe y se ha dejado transformar por las Escrituras, cuya consecuencia es que la naturaleza humana que tiene en común con Cristo lo hace unirse en un mismo espíritu con él y, por ende, con el Padre ${ }^{59}$. De este modo, el hombre espiritual se transforma desde Cristo por la acción del Espíritu Santo ${ }^{60}$, el cual proporciona la gracia de la unión entre el Infinito y el finito -aunque de ninguna manera se vincula esencialmente a la naturaleza divina-, ya que, para el cusano, es el Espíritu el que permite la unión infinita entre Dios Padre y Dios Hijo ${ }^{61}$.

En este punto parece claro que el ver de Dios y la posibilidad que este entrega al hombre para verle, responde ciertamente a su condición de Padre, el cual le ha dado la gracia del ser, gustando con ello su amor

\footnotetext{
54 Cf. VD 112.

55 Cf. VD 119.

56 Cf. VD 106. En contrapartida, las consecuencias de la separación con Dios, tiene como consecuencia el no-ser, puesto que él nos da el ser y junto con ello la vida, entonces en el rechazo de la revelación está la imposibilidad de la felicidad, el amor y por tanto de la salvación. Cf. VD 14.

57 Cf. VD 113.

58 Cf. Col 3,9.

59 VD 93.

60 A la luz de San Pablo: "Mas vosotros no estáis en la carne, sino en el espíritu, ya que el Espíritu de Dios habita en vosotros. El que no tiene el Espíritu de Cristo, no le pertenece", Rm 8,9.

61 Cf. VD 87. Al Espíritu Santo Nicolás de Cusa le llama “nexo” Cf. VD 84.
} 
y su bondad. Por su parte, en Cristo y en el Espíritu, es posible llegar al Padre y alcanzar una plena comunión con él ${ }^{62}$. De esta forma, Nicolás de Cusa descubre al Dios Trino, al cual llama Unitrino, como una forma de expresar el misterio de Dios, donde existen tres personas totalmente unidas pero, a la vez, distintas ${ }^{63}$. El Cardenal utiliza el ejemplo del amor para referirse a cada una de las personas divinas: al Padre le llama el Dios amante, es decir, la acción propia del amor que engendra al Hijo; a éste le llama Dios amable, sujeto del amor del Padre; y el amor que une a ambos es el nexo, y esa es la función que el cusano atribuye al Espíritu Santo ${ }^{64}$.

Además, para el cusano, el Espíritu Santo ejerce una misión ad extra de la Trinidad, función que él va a ejemplificar de la siguiente manera: el motor inmóvil correspondería al Padre y el móvil simbolizaría al Hijo, el Espíritu no se asemejaría ni con lo uno ni con lo otro, sino que equivaldría al movimiento y, por ende, unir el misterio de Dios al misterio del hombre ${ }^{65}$; e incluso más, la acción de comunión que se da es también en orden a Dios y a la Iglesia.

Al incorporar el elemento del Espíritu Santo, Nicolás de Cusa, nuevamente vuelve al tema del alter; pues, así como el espíritu del yo se une al espíritu de Dios, de la misma manera otros yo se unen al espíritu divino. En este sentido, aunque en la contemplación del ícono me encuentre yo solo, no se puede dejar de considerar que hay otros que también le miran y experimentan lo mismo que me sucede a mí. Para el cusano el otro se presenta como una oportunidad de aprendizaje y de ayuda, pues de hecho existen diversos espíritus intelectuales que no se ejercitan en otra cosa más que en buscar a Dios, de allí que los hombres comparten sus experiencias y conocimientos con otros, y de esa manera se incrementa el conocimiento del Infinito ${ }^{66}$. Es en esta perspectiva donde aparece la Iglesia, como comunidad de los espíritus intelectuales que buscan

\footnotetext{
Cf. Jn 20,21.

63 Cf. VD 74. Nicolás de Cusa siempre va enfatizar el hecho que Dios es uno, de allí que el profesor Beierwaltes señale que: «La unión, de motivación cristiana, de "unitas" y "trinitas" en la "sanctissima tri-unitas", es un tema que acompaña al Cusano toda su vida», W. Beierwaltes, Cusanus..., 56.

64 Cf. VD 83.

65 Cf. VD 84.

66 Cf. VD 117.
} 
a Dios, dan testimonio de él y además transmiten desde los apóstoles la $\mathrm{fe}$, es decir, la Iglesia también es presentada como una instancia de ayuda para el conocimiento de Dios ${ }^{67}$.

En síntesis, se puede afirmar, a partir de la obra del cusano, que existen diversos puntos de unión que posibilitan al hombre el encuentro con el Dios Unitrino, a saber: las creaturas como epifanías del Creador, Jesucristo quien abre el camino a la adopción filial y el Espíritu Santo como nexo. Sin embargo, no se puede perder de vista que la experiencia de la mirada finita, que se proyecta hacia el Infinito en la vida terrenal, siempre será una aproximación, aunque esta tenga sus grados de perfección, porque la plenitud viene dada, ciertamente, por la visión bienaventurada.

\section{El Mirarse a sí Mismo DESDE EL INFINITO}

Este proceso que se ha desarrollado en los dos primeros acápites, donde el Infinito, a partir de su propia iniciativa, ha permitido que el hombre le toque con su mirada, tiene sus consecuencias en el yo. Esta transformación la hace patente Nicolás de Cusa cuando afirma que el hombre que alcanza a mirar el rostro de Dios, inevitablemente, se ve a sí mismo porque ve su propia verdad ${ }^{68}$. Para ilustrar esta realidad el cusano va a utilizar la imagen del espejo, al modo de San Pablo, cuando señala que al tiempo presente "vemos en un espejo, en enigma. Entonces veremos cara a cara. Ahora conozco de un modo parcial, pero entonces conoceré como soy conocido" ${ }^{69}$. De modo que, dirá el cusano, si alguien mira en este espejo ve su propia forma, en la forma de las formas, o sea desde Dios mismo ${ }^{70}$.

${ }^{67}$ Cf. VD 83. Con respecto al tema de la Iglesia Cf. Nicolás de CusA, De docta ignorantia, L. 3, cap. XII y Nicolás DE CusA, De concordia catholica, trad. José Ma de Alejandro Lueiro (Centro de Estudios Constitucionales, Madrid, 1987) L. I, cap. I-VI.

68 Cf. VD 18.

691 Cor 12, 13. También el profesor Ángel Luis González señala que en esta imagen del espejo Nicolás de Cusa tiene como fuente a Platón especialmente en la obra el Alcibiades Mayor, cf. A. GonzÁlez, "Ver e imagen del ver acotaciones sobre el capítulo xv del De visione Dei de Nicolás de Cusa”, en Anuario Filosófico 28 (1995) 635-636.

70 Cf. VD 63. 
$\mathrm{Al}$ respecto, es interesante el comentario que hace el profesor Beierwaltes, cuando señala que este mirarse en el espejo de parte del hombre no es un mirarse a sí mismo como una reproducción, sino más bien ver su figura en la verdad, porque se ve a partir de Dios que lo ha creado ${ }^{71}$. Y en este acto de creación, Dios ha hecho al hombre a imagen y semejanza suya, aspecto que el cusano explica en De visione Dei desde Cristo, pues sostiene que el Hijo es la exclusiva perfecta semejanza de Dios ${ }^{72}$; desde esta premisa, el cusano afirma que todos los hombres pueden hacerse semejantes a Cristo y, desde allí, constituirse en perfecta imagen de Dios ${ }^{73}$.

Ahora bien, esta condición de imagen y semejanza en el hombre no es presentada por el cusano como algo estático, sino que adquiere un nuevo dinamismo en Cristo, de hecho, en una obra anterior del Cardenal, llamada De mente del año 1450, aclara que la mente o alma racional es lo que ha sido creado a imagen y semejanza de Dios y se caracteriza por ser una imagen viva, por lo que dentro de ella posee una potencia que le permite perfeccionarse ${ }^{74}$.

En este sentido, el cusano se pregunta qué sucede con el hombre que Dios perfecciona, a lo que responde señalando que principalmente lo que hace Dios es infundirle, al ser humano, su espíritu de bondad para que pueda producir frutos ${ }^{75}$. El Cardenal ejemplifica esta afirmación con el poder del sol y los vegetales, de modo que solo en la potencialidad

71 Cf. W. Beierwaltes, Cusanus..., 198.

72 Al respecto señala San Pablo en su himno cristológico con el cual da inicio a la Carta a los Colosenses: "Él es Imagen de Dios invisible, Primogénito de toda la creación" Col 1,15. Además dirá Nicolás de Cusa en De possest: "Solo el Hijo de Dios es 'figura de la sustancia' del Padre, porque es todo lo que puede ser. La forma de Dios Padre no puede ser más verdadera o más perfecta, porque es el possest". Nicolás de Cusa, De possest, 58.

73 En este sentido señala el profesor González basado en la obra de W. Schulz, El Dios de la metafísica moderna, que: "La entera metafísica de Nicolás de Cusa se basa en última instancia en una consideración e interpretación de lo creado, y especialmente del hombre como imago Dei", A. GonzÁlez, "Ver e imagen...", 637.

74 Cf. Nicolás de Cusa, De mente (EUNSA, Pamplona, 2001) cap. IV-V. También es interesante al respecto el artículo de C. D’Amico, "Nicolás de Cusa, «De mente»: La profundización de la doctrina del hombre-imagen", en Patristica et medievalia XII (1991) 53-67; C. D’Amico, "El hombre como «secundus Deus»: forma única y reconstitución nocional de géneros y especies en el pensamiento cusano", en Veritas 44 (1999) 815-823.

75 Cf. VD 115. 
del fruto este se puede perfeccionar; lo mismo sucede con el hombre, en cuanto singularidad ${ }^{76}$, ya que es a partir de él mismo que Dios puede perfeccionarlo. Es por eso que en la oración más profunda de la contemplación el cusano exclama:

"Oh, Señor, suavidad de toda dulzura, has puesto en mi libertad que si yo quiero, yo sea yo mismo. Por, tanto si yo no soy yo mismo, tú no eres mío; de otro modo coartarías mi libertad, ya que tú puedes ser mío únicamente cuando yo sea yo mismo. Pero como has establecido esto en mi libertad, no me coartas, sino que esperas que yo escoja ser yo mismo. Por tanto de mí depende y no de ti Señor" ${ }^{\prime 77}$.

Nicolás de Cusa es enfático en afirmar que el ser yo mismo depende del hombre y esto radica particularmente en su libertad, porque incluso señala que Dios no puede donarse al yo si este no lo deja, pero no se trata solo de abrir la puerta del ser, sino que el permitir que Dios entre en la vida de la persona pasa por ser uno mismo. De allí que, en la superficialidad o falsedad del yo, Dios jamás podrá entrar en comunión con el yo, pues el ser finito necesita reconocer su verdad para mirar a Dios que es la verdad misma; pero esta opción es una decisión personal y radical, que le corresponde tomar a cada uno de los seres humanos. Esto no quiere decir que Dios no sea omnipotente, sino que en una relación de amor no puede haber coerción, porque sería todo lo contrario al amor; el cusano sitúa esta interacción amorosa en la relación filial, donde el Padre ha dado la libertad a sus hijos, porque él es la libertad misma, que permite incluso que el hombre se aleje y consuma su libertad en los deseos corruptos de los sentidos, sin embargo, jamás el Padre abandona a su hijo ${ }^{78}$.

"Sé tú mismo y yo seré tuyo"79, es la voz de Dios que resuena en el corazón de Nicolás de Cusa, de allí que, en el propósito de trazar el camino místico hacia la contemplación del rostro, se debe agregar este elemento de decisión crucial cual es, el ser yo mismo. Como se ha seña-

76 Concebir al hombre en su singularidad es muy importante para el cusano, pues deriva esta afirmación de su reflexión sobre lo uno, de lo que resulta como consecuencia la concepción de un hombre en su individualidad inconfundible. Cf. W. Beierwaltes, Cusanus..., 62.

77 VD 25.

78 Cf. VD 28.

79 VD 25. 
lado se trata de un ser yo mismo de cara a la verdad de Dios, por tanto es una prolongación del movimiento de la mirada infinita que al modo de un boomerang, hace que el finito se encuentre consigo mismo y de esa manera con Dios.

\section{LA FUERZA DE DESEO Y DE ATRACCIÓN}

Encontrarse consigo mismo lleva, inevitablemente, a que el ser finito se encuentre con la precariedad de su ser que, ciertamente, no se sustenta en sí mismo sino que en el Infinito absoluto; y, a la vez, la condición de libertad con la cual cuenta es, justamente, la que le permite alejarse de Dios ${ }^{80}$.

Ahora bien, para Nicolás de Cusa la acción propia de la libertad en que se rechaza la gracia divina la llama pecado, aunque considere que este hecho es inadecuado, porque para él lo propio de la libertad sería el camino hacia la conversión. El Cardenal afirma que el alejarse de Dios es lo que hace al hombre pecador y, por tanto, infeliz; ya que buscando la fuente de la vida, no acierta, pues la busca en las creaturas que no pueden dar la vida. El cusano considera esta realidad como ilógica, pues si no fuera por Dios el yo no existiría, en otras palabras, el error está en buscar la existencia en aquello que, al igual que a él, se le ha dado el ser como un don ${ }^{81}$. Ahora bien ¿dónde está el pecado? en rechazar a aquel que me ha dado la vida y el ser, desde allí se desprende que, en el fondo, el cusano tiene una concepción del pecado que define, principalmente, como la división entre el hombre y $\operatorname{Dios}^{82}$.

Para referirse al tema del pecado el cusano utilizará en De visione Dei, como telón de fondo, la perícopa bíblica del hijo pródigo ${ }^{83}$. Es así como, para él, el hecho de negar a Dios como Padre conlleva un rechazo a la relación filial, negando además todos los dones recibidos como verdaderos hijos de Dios en el Hijo. La consecuencia de esto es que la condición del hombre llega a ser aún peor, pues se priva a sí mismo del don de la

80 Cf. VD 14.

81 En el fondo es la idolatría que ridiculiza Isaías bajo el argumento que no son más que creaturas hechas por el mismo hombre: "se llenó su tierra de ídolos, ante la obra de sus manos se inclinan, ante lo que hicieron sus dedos", Is 2,8.

82 Con respecto a la concepción cusana del pecado ver G. Cuozzo, "Il tema del "peccato originale» nella teoría della conoscenza di Cusano", en J. MachetTA - C. D’Aмico (eds.), El problema del conocimiento... , 121-139.

83 Cf. Lc 15,11-24. 
libertad que le permite ser dueño de sí; entonces, su situación es deplorable, ya que esta libertad se convierte en esclavitud, pues es sometida al príncipe de este mundo. Además, en esta situación de pecado, el hombre está condenado a una miseria profunda, que llega a deshumanizarlo, por lo que las circunstancias existenciales del hombre pecador están lejos de constituirse en una vida feliz ${ }^{84}$.

A pesar de lo anterior, el cusano manifiesta que siempre está la posibilidad de la conversión, ya que Dios no puede retirar del hombre su mirada, pues de lo contrario dejaría de existir. Porque una cosa es que el ser singular esté lejos de Dios y otra cosa es que Dios desaparezca. De este modo, el hombre puede realizar el movimiento de apartarse pero, al mismo tiempo, existe otro de retorno, sin embargo, lo más originario está en el actuar de Dios, ya que él va por delante y antes que el hombre vuelva a fijar su mirada ya Dios posa la suya sobre él ${ }^{85}$.

Así pues, para el cusano, Dios está constantemente de cara al hombre y quiere su conversión, con el único propósito que sea feliz, es por eso que lo sigue con su mirada. Sin embargo, esto no es más que una analogía del hecho que realmente Dios vive en cada hombre, de modo que esta figura usada por el Cardenal, para manifestar que Dios está continuamente tras el hombre, es una exteriorización de una realidad profundamente interna anidada en el ser más íntimo de la persona ${ }^{86}$. De allí que Dios no deja solo al hombre concediéndole el deseo santo de permanecer a su lado ${ }^{87}$, invitarlo a esto es canalizar sus deseos hacia Dios, es descubrir que solo él puede saciar al hombre, de allí que el Cardenal siguiendo a San Agustín ${ }^{88}$ señale que: "Mi corazón no logra

\section{Cf. VD 26. \\ Cf. VD 15.}

86 En este sentido señala Nicolás de Cusa en otra de sus obras: "Así, nuestra mente, aunque al principio de su creación no tenga el esplendor actual del arte creador en la trinidad y la unidad, tiene sin embargo concreada esa potencia por medio de la cual, estimulada, puede hacerse más conforme a la actualidad del arte divino", Nicolás de Cusa, De mente, cap. XIII.

87 Cf. VD 43.

88 En esta cita se aprecia claramente la influencia de las Confesiones de San Agustín en De Visione Dei, ya que el obispo de Hipona inicia su obra aludiendo a la precariedad humana, la grandeza de Dios y la posibilidad del encuentro, cuando dice: "Grande eres, Señor, y muy digno de alabanza (Sal 145,3); grande es nuestro Señor, todo lo puede, nadie puede medir su inteligencia (Sal 147,5). Y se atreve alabarte el ser 
descansar, Señor, porque tu amor lo ha inflamado con un deseo tal que solamente en ti puede descansar" ${ }^{\prime \prime 9}$.

En este testimonio del cusano es posible vislumbrar cómo la categoría deseo aparece como una experiencia de trascendencia del hombre, pues éste no se podrá saciar con algo distinto que no sea Dios, ya que si el hombre busca saciarse fuera de él siempre va a continuar estando insatisfecho en su deseo ${ }^{90}$. Se trata, para el cusano, de un descanso en plenitud, el cual está unido al amor que proviene de Dios. Que el hombre pueda alcanzar este descanso del espíritu es una gracia enorme, pues significa haber encontrado realmente a aquel que le da la vida y, de ese modo, saciar toda su sed de amor ${ }^{91}$.

Si bien es cierto el deseo es propio del hombre, es necesario consignar que ha sido dado por Dios y su finalidad es llevarlo a Dios ${ }^{92}$. El cusano no tiene problema de afirmar que es Dios mismo quien conduce al hombre hacia él, porque, en su lógica, el ser humano encuentra su plenitud solo en Dios; por tanto, no habría lesiones a temas como la autonomía o el empequeñecimiento de la dignidad humana, debido a su ligación con la divinidad ${ }^{93}$. Esta racionalidad del cusano lo ubica, según Balthasar en la misma línea de algunos autores como Gregorio Magno y Gregorio de

humano, parte insignificante de tu creación, precisamente el ser humano que lleva alrededor suyo la mortalidad, que lleva a flor de piel la marca de su pecado y el testimonio de que Tú resistes a los orgullosos (1P 5,5). Sin embargo, se atreve a alabarte un hombre, parte insignificante de tu creación. Y tú mismo eres quien le estimulas para que encuentre deleite en alabarte, porque nos has creado orientados hacia $\mathrm{Ti}$, y nuestro corazón estará intranquilo hasta que descanse en Ti”, SAN Agustín, Confesiones (BAC, Madrid, 1956) I, 1.

VD 27.

Con respecto al tema del deseo, cf. VD, cap. XVI: Si Dios no fuese infinito no sería el fin del deseo.

A la luz del diálogo entre Jesús y la mujer samaritana: "Jesús le respondió: Todo el que beba de esta agua, volverá a tener sed; pero el que beba del agua que yo le dé, no tendrá sed jamás, sino que el agua que yo le dé se convertirá en él en fuente de agua que brota para vida eterna", Jn 4, 13-14. La misma idea se repite en el discurso de Jesús sobre el pan de vida: "Yo soy el pan de la vida. El que venga a mí, no tendrá hambre, y el que crea en mí, no tendrá nunca sed”, Jn 6, 35.

92 Cf. VD 69.

93 Al respecto ver el trabajo de L. Dupré, "Nature and Grace in Nicholas of Cusa's Mystical Philosophy", en American Catholic Philosophical Quarterly LXIV (1990) 153-170. 
Nisa, donde esta tensión-hacia es colmada por Dios, o de lo contrario se vuelve un interminable tormento, pues el ser finito experimenta que su ser racional nunca puede llegar a su plenitud en esta vida ${ }^{94}$.

Para ilustrar esta realidad el cusano utiliza imágenes como el fuego que no se apaga y arde constantemente, de la misma forma ocurre con el amor y la verdad en el interior del hombre ${ }^{95}$. Pero lo más importante es señalar que, hacia el final de la obra, el cusano señala que este deseo puesto por Dios en el hombre en definitiva es una acción del Espíritu Santo, quien lo está llamando continuamente, de allí que contemplando a Dios señala: "Me confortas con tu Espíritu Santo; a través de él, me inspiras decisiones de vida, santos deseos"96.

Nicolás de Cusa enfatiza frecuentemente, en De visione Dei, el hecho que Dios ha puesto en el corazón del yo el deseo de lo Infinito pero, al mismo tiempo, va a señalar que el Infinito ejerce una fuerza de atracción hacia el yo. Siguiendo al evangelista Juan ${ }^{97}$ señala "Nadie puede llegar al Padre, si no es atraído por el Padre" 98 y esto lo hace en el Hijo, quien es el único medio a través del cual el Padre atrae a todos los hombres.

Ahora bien, el objetivo de dicha atracción no es otro que anticipar la vida eterna y la plenitud de la felicidad, para lo cual el cusano afirma que Dios va anticipando la vida gloriosa con imágenes que, generalmente, tienen relación con la cena, los sabores y los aromas99.

Entonces, tenemos dos fuerzas que se dan entre el Infinito y el finito, a saber, deseo y atracción, pero ¿qué sucede cuando estas fuerzas logran el objetivo de atraer al yo hacia Dios y a la vez el yo, en su libertad, desea unirse a Dios? No sucede otra cosa, por así decirlo, que estas fuerzas desatan un torbellino a modo de un tornado, donde se ejerce una fuerza centrípeta cuyo eje articulador no es otro que el amor ${ }^{100}$. Es por este

94 Cf. U. Balthasar, Gloria, v.5 (Encuentro, Madrid, 1988) 213.

95 Cf. VD 67.

96 VD 119.

97 Cf. Jn 12, 32.

98 VD 93.

99 Cf. VD 1. 119.

$100 \mathrm{Al}$ principio de la obra el cusano señala: “¿Y qué es mi vida, Señor, sino ese abrazo con el que la dulzura de tu amor me abraza amorosamente? Amo supremamente mi vida porque tú eres la dulzura de mi vida”, VD 11. 
motivo que la obra termina con una verdadera plegaria de parte del autor, en cuanto que pide ser atraído constantemente por Dios: "Atráeme, Señor, -ya que nadie podrá llegar a ti si no es atraído por ti- para que, atraído, sea liberado de este mundo y me una a ti, Dios absoluto, en la eternidad de la vida gloriosa" ${ }^{101}$.

\section{El CAMINO Místico DE LA CONTEMPLACión DEL ROSTRO}

El camino místico que propone Nicolás de Cusa en De visione Dei parte de una experiencia religiosa muy simple, cual es el contemplar una imagen del rostro de Dios. A partir de aquí, se puede desprender todo un itinerario místico, que en este último acápite se presentará a modo de un esbozo sistemático.

Primer momento, la posibilidad de mirar a Dios: El presupuesto que ha de tener presente el hombre, que contempla una imagen del rostro de Dios, es que Dios toma la iniciativa, ya que el poder ver el rostro divino es porque el Creador, que le ha regalado el ser, le permite la visión. Esta posibilidad hace al hombre descubrir un amor inmenso de parte de Dios, lo cual le regala entender que este encuentro de miradas posee un carácter personal y gratuito.

Segundo momento, mirada del hombre: Al dirigir su mirada a Dios el hombre comienza su camino de contemplación. Hay que tener presente que el ícono, para el cusano, no es más que una analogía, pues lo propio de Dios es ser invisible. Entonces ¿dónde comienza el ser humano el camino de contemplación del rostro de Dios? A esta interrogante el cusano responde que por medio de las creaturas es posible contemplar a Dios, es aquí donde aparece el alter como un medio para ver a Dios. Sin embargo, hay que tener en cuenta que se trata de una forma velada aún, porque el ser finito no tiene otro camino para acceder a Dios, que aquel que el mismo Dios le concede para ver más allá. Es aquí donde Nicolás de Cusa da el salto cualitativo a la gracia como posibilidad epistemológica trascendente.

Ver en la gracia es reconocer en primer lugar la precariedad del intelecto humano, lo que el cusano llama la docta ignorancia, desde aquí se puede aceptar la guía divina dada en Jesucristo, pues en su persona están unidas la naturaleza divina y humana, lo que abre al hombre la posibi-

101 VD 119. 
lidad de participar de la vida de Dios, constituyendo al yo/finito en hijo del Padre. La filiación adoptiva es posible gracias al nexo por excelencia que es el Espíritu Santo, condición que se nutre por medio de las enseñanzas de Cristo consignadas en la Escrituras, provocando en el creyente un acercamiento aún más profundo con el Padre. Este encuentro filial entre el yo y el Padre, para Nicolás de Cusa, no es una realidad individual y única pues es compartido por otros que también experimentan la filiación, a este conjunto el cusano lo designa como la Iglesia.

En este proceso la mirada del hombre se vuelca hacia Dios, descubriéndolo como Padre a través de Cristo en la comunión del Espíritu Santo. Es aquí cuando el ver finito se encuentra con el Dios Unitrino.

Tercer momento, conversión: El encuentro, entre la mirada del Dios Unitrino y la mirada del hombre dirigida hacia él, produce una transformación interior en el yo/finito, en tanto cuanto se descubre como imagen y semejanza de Dios. Es por este motivo que, sostiene el cusano, mientras más sea yo mismo, más puedo ver a Dios; pero, este ser yo mismo, se transforma en una tarea continua, donde la contemplación mística tiene una constatación práctica en mi crecimiento personal. En este proceso el hombre se hace cristiforme ${ }^{102}$, en cuanto encuentra su plenitud en Cristo.

Cuarto momento, combate espiritual: En este camino hacia la configuración con Cristo, el yo experimenta una tensión permanente entre el deseo y la atracción. Cuando ambas fuerzas confluyen hacia el encuentro filial entre el Padre y el yo/finito el proceso de contemplación y conversión fluye, para el cusano, de manera adecuada. Sin embargo, cuando el deseo es contrario a la atracción del Dios Unitrino, el hombre tiende a alejarse de Dios, situación que Nicolás de Cusa designa como pecado. De allí que, permanentemente, el yo tenga que dar un combate espiritual, en el sentido de aunar su deseo al poder de atracción que Dios mismo ejerce hacia él.

\section{ConClusión}

Teniendo en cuenta el propósito que declara Nicolás de Cusa, cuando escribe su obra De visione Dei, de acercar a los monjes benedictinos de Tegernsee a la teología mística, se puede afirmar que a través del análi-

102 Término ocupado por Nicolás de Cusa en De Possest 32; 33; 39. 
sis del texto se han podido desentrañar los misterios del encuentro del hombre con Dios, no solo para los monjes de su tiempo sino también para los creyentes de hoy.

$\mathrm{Al}$ abordar los temas que configuraron el artículo, ha sido posible descubrir el camino de acceso al conocimiento de Dios, propuesto por el cusano, que va más allá de lo meramente intelectual, pues sus reflexiones permiten proyectarse hacia un conocimiento experiencial o místico del misterio divino. Este camino, para el Cardenal, está marcado por la gracia, presentada en un contexto de contemplación visiva, que permite a la creatura acceder al Creador, como Dios Unitrino, y, desde allí, comprenderse a sí mismo de mejor manera.

Este recorrido místico puede realizarse, en sus primeras fases, sin presuponer la fe, ya que el cusano afirma constantemente que la creación es una epifanía de Dios, que permite al hombre acceder por medio de los efectos a la Causa; de este modo, se puede apreciar que la posibilidad de encuentro se abre a toda la humanidad. Ciertamente, se trata de una experiencia inicial de Dios, que se hará más plena por medio del salto cualitativo de la fe, iluminado por el acontecimiento de Jesús de Nazareth, es aquí donde el cusano establece una unión crucial entre mística y gracia. Junto con lo anterior, se destaca el carácter personal que el encuentro adquiere en Cristo, pues en el Hijo el hombre descubre su filiación y pertenencia al Padre, todo ello movido por el Espíritu Santo.

A su vez, en su exposición el Cardenal no permite que el lector reduzca este camino místico a una condición puramente voluntarista, pues la gracia de Dios es condición sine qua non para avanzar hacia el encuentro pleno entre el Infinito y el finito; es más, para el cusano, sin la gracia ni siquiera existiría el hombre. También se puede afirmar que el itinerario místico, propuesto por el cusano, no se puede reducir a un mero encuentro dentro de las coordenadas espacio temporales de la vida humana, ya que nunca pierde de vista la dimensión escatológica del camino místico, en tanto cuanto este proceso no hace más que abrir el cielo en razón de tomar en peso que el ser humano está llamado a la visión definitiva de Dios, donde podrá participar plenamente de la gloria divina y la dicha más plena.

Por último, queda en evidencia que para Nicolás de Cusa la mística no es una realidad reducida al éxtasis o experiencias sobrenaturales de algunas élites; sino que, por el contrario, para el cusano todo ser huma- 
La contemplación del rostro como camino místico en De visione Dei de Nicolás de Cusa 485

no puede recorrer el camino místico de la contemplación, entendido como un encuentro progresivo del hombre con Dios, que comienza con la epifanía de la creación y culmina, por medio de la gracia, en la visión beatífica. 
Resumen: El artículo pretende descubrir el itinerario místico que se desprende de la lectura de la obra De visione Dei de Nicolás de Cusa. Esta tarea es factible, pues el mismo autor propone encontrarse con el Dios de Jesucristo a través de una forma, aparentemente, muy simple: la contemplación de un ícono. A partir de allí, va mostrando un camino de crecimiento espiritual que experimenta la persona que mira la imagen del rostro de Dios, desde lo cual emergen las distintas etapas del camino místico que subyace en la obra.

Palabras clave: Mística, visión de Dios, encuentro, contemplación.

Abstract: This article pretends to reveal the mystic itinerary which can be found in Nicholas of Cusa's De visione Dei. The very same author proposes to find himself with the God of Jesus Christ through an apparently simple form: the contemplation of an icon. He then indicates a path of spiritual growth that is experimented by the person who looks at this image of God's face. From here on emerge the different steps of the mystic path which underlie in this work.

Keywords: mysticism, vision of God, encounter, contemplation 